\title{
Diagnosis \& treatment of mechanical obstruction of Eustachian tube
}

\begin{abstract}
Generally, most people who experience problems report such things as 'hearing loss' or/ and 'ear fullness' or/and 'dizziness (vertigo) or/and 'tinnitus' or/and 'headache (migraine)'. In all cases, some process should be performed to rule out possible mechanical causes for above mentioned symptoms such as middle ear effusion or/and Eustachian tube obstruction before all. Ideally normal middle ear cavity pressure with balance between both ears. This is the essential prerequisite for tests of vestibular function, tinnitus, headache, ear fullness, etc. If so, what is first, necessary and sufficient for it. Eustachian tube catheterization (socalled 'Rosenmuller method'). This may be of both diagnostic and therapeutic value.
\end{abstract}

Keywords: hearing loss, ear-fullness, dizziness, tinnitus, headache, eustachian tube catheterization
Volume I Issue I - 2014

\author{
Hee-Young Kim \\ Otolaryngology, Kim ENT Clinic, Republic of Korea
}

Correspondence: Hee-Young Kim, Otolaryngology, Kim ENT Clinic, 2nd fl. I I 9, Jangseungbaegi-ro, Dongjak-gu, Seoul, I 56-806, Republic of Korea, Tel +82-02-855-754I, Fax +82-02-855-7542 Email kheeyoung@gmail.com

Received: October 19,2014 | Published: November 19, 2014

\section{Introduction}

Generally, most people who experience problems report such things as 'hearing loss' or/and 'ear fullness' or/and 'dizziness (vertigo) or/and 'tinnitus' or/and 'headache (migraine)'. These are the combination of symptoms that are complained commonly by otolaryngologic patients. First of all, we have to check the state of middle ear and Eustachian tube. As we know, Eustachian tube dysfunction is considered the major etiologic factor resulting in the development of middle ear disease. Blocked Eustachian tubes can cause several symptoms, including ears that hurt and feel full, ringing or popping noises, hearing problems, feeling a little dizzy. ${ }^{1}$ Dizziness or vertigo from Eustachian tube obstruction can be explained by increase of inner pressure of vestibular organ. It is because negative middle ear pressure gives rise to the retraction of tympanic membrane, and it makes the stapes push the oval window. Improvement of tinnitus after Eustachian tube catheterization can mean that the tinnitus is from the hypersensitivity of cochlear nucleus following decrease of afferent nerve stimuli owing to air-bone gap. ${ }^{2}$ When I need to explain the cause of headache from negative middle ear pressure, I support the theory of 'Sinus headache'. ${ }^{3}$ Middle ear cavity and mastoid cavity are named on the basis of anatomy. However, if we view things from a different angle, we can regard them as one of 'paranasal sinuses' like maxillary sinus or frontal sinus in a view of physiology and function. The reason I mentioned 'migraine', because my many patients complained to me so. I guess that it was misdiagnosed before meeting me.

Mechanical obstruction of the Eustachian tube may be either intrinsic or extrinsic. Intrinsic mechanical obstruction is usually caused by inflammation of the mucous membrane lining of the Eustachian tube or an allergic diathesis causing edema of the tubal mucosa. Extrinsic mechanical obstruction is caused by obstructing masses such as hypertrophic adenoid tissue or nasopharyngeal tumors. ${ }^{4}$ In these cases, some process should be performed to rule out possible mechanical causes for such as middle ear effusion or/ and Eustachian tube obstruction before all. Furthermore, ideally normal middle ear cavity pressure with balance between both ears is the essential prerequisite to be checked before any other tests for vestibular function, tinnitus, ear fullness, sensorineural hearing loss, headache, earaches, itching sensation of ear, migrainous vertigo, etc. What is first, necessary and sufficient for it? Eustachian tube catheterization (so-called 'Rosenmuller method').

How Eustachian tube catheterization is done? This procedure is more than a century old and was earlier routinely done to check patency of the Eustachian tube. The tip of the catheter is inserted into the nose and passed along the floor of the nasal cavity till it touches the posterior pharyngeal wall. The tip is now in the nasopharynx. At this point, the tip is rotated $90^{\circ}$ laterally so that it touches the Rosenmuller fossa behind the Eustachian tube in the lateral wall. The tip is pulled slightly, and passes over a gentle slope, so that it enters the opening of the Eustachian tube. A Politzer bag or ventilator is attached to the other end of the catheter. Air pushed from it can be heard rushing into the ear if the Eustachian tube is patent. The medial and lateral rotations that appear to complicate the procedure were actually designed to avoid the tubal elevation located behind the tubal opening since the tip cannot be seen once inserted into the nose. The original procedure was a blind one, with only the metal ring to indicate the direction of the catheter's tip. But the procedure can also be done under endoscopic guidance. The important thing to remember is that the method only tests patency of the Eustachian tube and does not reflect on its function. ${ }^{5}$

Symptom is just a subjective sign depending on the individual. Minimal obstruction of Eustachian tube or minimal change of middle ear pressure can make above-mentioned symptoms, and those can be complained by patients 'within normal limit' of tympanometry. What 'within normal limit' as the result of tympanometry is for? I believe it is necessary, but not sufficient. Nasal fiberscopy has the limit for examination of inner obstruction on Eustachian tube. When patients complain some symptoms, we suspect the possible cause for it. If we remove the possible cause, we can realize that those symptoms disappear. Can what is more certain than that this diagnostic method? I had experienced the blood smeared by the catheter after the procedure. Suspecting it as 'touch bleeding' in my technique, I asked further evaluation. The result was nasopharyngeal carcinoma.

\section{Conclusion}

In conclusion, it is essential that doctors know that Eustachian tube catheterization must be practiced in the proper technique, for 
every patient complaining 'hearing loss' or/and 'ear fullness' or/and 'dizziness (vertigo)' or/and 'tinnitus' or/and 'headache (migraine)', etc. This may be of both diagnostic and therapeutic value. Ideally normal middle ear cavity pressure with balance between both ears. This is the essential prerequisite for tests of vestibular function, tinnitus, headache, ear fullness, earaches, itching sensation, etc. Nowadays, however, this Eustachian tube catheter is forsaken by most otolaryngologists. At the same time, they throw away it with the concept for its necessity. Above-mentioned concept is the grounds and spirit in order to keep the Eustachian tube catheter, and should be continued. To me, the metal ring of Eustachian tube catheter looks like 'The one ring', but it is one ring that we should never destroy.

\section{Acknowledgments}

None.

\section{Conflicts of interest}

The authors declare that there is no conflicts of interest.

\section{References}

1. Pai S, Parikh SR. Otitis media. In: AK Lalwani (Ed.), Current Diagnosis and Treatment Otolaryngology Head and Neck Surgery. ( $3^{\text {rd }}$ edn), McGraw-Hill, USA: New York; 2012. p. 674-681.

2. Heller MF, Bergman M. Tinnitus aurium in normally hearing persons. Ann Otol Rhinol Laryngol. 1953;62(1):73-83.

3. Cady RK, Schreiber CP () Sinus headache or migraine? Considerations in making a differential diagnosis. Neurology. 2002;58(9 Suppl 6):S10 S14.

4. Johnson J, Broniatowski M, Eisele D, et al. Maintenance manual for lifelong learning, Otitis media. ( $2^{\text {nd }}$ edn), American Academy of Otolaryngology-Head and Neck Surgery Foundation. Kendall/Hunt Publishing Company, Dubuque, USA, 2002. p. 139-140.

5. Noh K. Otolaryngology-Head and Neck Surgery, Problem and assessment. Ilchokak, Seoul, Republic of Korea, 1995. p. 14-15. 